\title{
A Study of How High-Speed Railway Affects County Industry Development
}

\author{
Jintao Ren \\ School of Economics, Jinan University, Guangzhou, China \\ Email:619589822@qq.com
}

How to cite this paper: Ren, J.T. (2018) A Study of How High-Speed Railway Affects County Industry Development. Open Journal of Social Sciences, 6, 69-80. https://doi.org/10.4236/jss.2018.65006

Received: April 9, 2018

Accepted: May 13, 2018

Published: May 16, 2018

Copyright $\odot 2018$ by author and Scientific Research Publishing Inc. This work is licensed under the Creative Commons Attribution International License (CC BY 4.0).

http://creativecommons.org/licenses/by/4.0/

\begin{abstract}
Since the first Chinese high-speed railway was built in 2008, the high-speed railway industry has developed rapidly recently. Based on "China railway yearbook", The map of China's railway network, "China statistical yearbook" in county level, and the "China Regional Economic Statistics Year book", we collect and sort out the various economic and society indexes of the county in China, and we set up the national city at the county level panel data, using Two-way Fixed Effect model to estimate the policy effect on the county which built the high-speed railway station. Based on the research of panel date, we can get several conclusions. Firstly, building a high-speed railway will promote the economic growth of the cities at the county level. Secondly, the opening of high-speed railway has positive and significant policy effect on the three main industries of county-level cities, especially the development of tertiary industry. Finally, the construction of high-speed rail has a strong policy impact on the county-level cities in the four regions of the eastern, western, central and northeastern regions. Among them, the construction of a high-speed railway site will promote the economic growth of the county-level high-speed rail station cities in the central region and the policy effect on the development of the tertiary industry is the strongest.
\end{abstract}

\section{Keywords}

Build High-Speed Railway, Economic Development, Industrial Development

\section{Introduction}

"If you want to be rich, build a railway. If a train comes here, then the treasure follows". The government officials or the ordinary people always think that "you can get rich as long as you build a railway" (Abhijit Banerjee et al., 2009). Research finds that being close to the traffic network can significantly increase the 
per capita GDP growth rate, which has a great positive impact [1]. As we all know, railway is a national important infrastructure, it's really a comprehensive transportation, it's one of daily and popular means of transportation, it's essential for the people who frequently travel to somewhere in daily life, and it's the important carrier of national economy operation. It plays an irreplaceable role in promoting the sound and fast development of our country in economy and society. Benjamin Faber (2014) found that the impact of connecting the national system network is relatively negative, that is, the GDP growth, industrial added value, government revenue, and non-agricultural added value of the county-level cities connected to the national system network must be obvious. Cities lower than county-level do not have access to the national system network. The results of the study show that the construction of high-speed railways can improve the conditions of transportation and improve the convenience of inter-city contacts. However, everything has advantages and disadvantages. The construction of high-speed rails is not necessarily a sufficient condition for urban economic development [2]. The transportation infrastructure investment is often regarded as one of the prerequisites for economic development. Investment in transportation infrastructure is an effective means to drive economic growth and it is a magic weapon to stimulate economic development. Therefore, experts and scholars engaged in economic research focus on the relationship between infrastructure investment and local economic development. Donaldson, Dave and Richard Hornbeck (2016) studied the impact of historical railroads on the US economy. The study found that the value of the agricultural land at the county site of the site will increase substantially with the continuous expansion of the regional railway network and the increase in market access to the county seat. However, if there is no railway, it is expected that the population will be greatly reduced and the level of consumer welfare will also be significantly reduced [3] [4].

\section{Summary of Development of the High-Speed Railway}

\subsection{The Definition of High-Speed Railway}

On October 1 in 1964, first high-speed railway in the world, the Shinkansen, was successfully developed and officially opened by Japan. It marks the arrival of a new era, the era of high-speed railway. Compared with the developed countries such as Japan, Germany and France, China's high-speed railway construction started relatively late, but the speed of China's high-speed railway development has shocked the world.

The definition of high-speed railway. Due to the different standards of various indicators, the definition of high-speed railway is different in different countries. National railway administration in our country defines it as: the new building, the speed of 250 kilometers or more (passenger dedicated railway operation speed shall be not less than 200 kilometers per hour) in the early of the emu train dedicated railway; Foreign standards are different. The lines are divided 
into old lines and new lines. The speed limit is 200 kilometers per hour and 250 kilometers to 300 kilometers per hour. In 1985, the Geneva agreement stipulates that the newly built passenger and freight train will be more than 250 kilometers per hour, while the newly built passenger line will have a speed of more than 350 kilometers per hour.

\subsection{Overview of the Development of High-Speed Railway}

In the early time of the $20^{\text {th }}$ century, at that time trains were running at a low speed. It was "very rare" to reach even more than 200 kilometers per hour. Until the Shinkansen system was opened in Japan in 1964, which was marked the birth of the first high-speed rail system in history that was faster than 200 kilometers per hour.

From 1964, the world's first recognized high-speed railway began to operate in Japan, and the development of high-speed railway has experienced three major waves.

\section{The first wave of development: from 1964 to the 1990s.}

On April 5, 1959, the Japanese Shinkansen high-speed rail system was to start building, was formally opened on October 1, 1964, marking the first in the true sense of the world's high-speed rail formally completed, and it also marked the world railway development into the "high-speed railway age". After Japan successfully built the Shinkansen high-speed railway, France, Italy and Germany followed suit and began to build high-speed railways.

The second wave of development: from 1990 to the mid-1990s.

During this period, many countries in the world began to large-scale building railways, especially most of the developed countries of Europe, such as France, Germany, Italy, Spain, Belgium, the Netherlands, Sweden, Britain and so on, gradually formed a high-speed rail network in Europe.

\section{The third wave of development: from the mid-1990s to the present.}

High-speed railway has set off a wave of development in the world, including Asia, North America and Australia, among which South Korea, Taiwan, China, the United States and Australia have developed rapidly.

The main countries in the world build high-speed rail way like these: Japan: after the success of the first high-speed railway in the world in 1964, Japan continuously increased the Shinkansen and operated more than 2600 kilometers. Germany: Germany has the second highest number of high-speed rail services in the world. France: after years of development, France now has six high-speed lines. The United States: relatively late, but after realizing the advantages and advantages of building high-speed railway, we began to pursue and develop high-speed railway with American characteristics. However, the us aviation industry is more developed, and the construction of high-speed rail will change the original traffic pattern and break the relative balance, which will also involve major conflicts of interest. South Korea: South Korea's national high-speed railway runs more than 800 kilometers. Taiwan: China Taiwan high speed railway 
operating mileage is $345.2 \mathrm{~km}$.

\subsection{The Development of High-Speed Railway in China}

China's development of high-speed railway, with its own regulations and standards, it can't be completely equivalent to other countries. Compared with some developed countries in the world, the development and construction of China's high-speed railway has the characteristics of late development and rapid development, which has shocked the world rapidly.

In January 2004, the state council executive meeting to discuss and principles through the first in the history of the medium and long-term railway network planning, put forward the construction in the planning "been horizontal" the idea of fast passenger dedicated line network.

In November 2007, the state approved the long-term development plan for comprehensive transportation network, and it determined that the total size of the railway network would reach more than 120,000 kilometers by 2020 .

On August 1, 2008, the Beijing-Tianjin inter-city railway was officially opened to traffic, marking the birth of China's first high-speed railway with complete intellectual property rights and world-class standards.

In October 2008 countries approved the "long-term railway network planning adjustment (2008)", determine to the 2020 national railway mileage to reach more than $120,000 \mathrm{~km}$, including passenger dedicated line reaches more than 16,000 kilometers.

On December 26 in 2009, the Wuhan-Guangzhou high-speed railway of Beijing-Hong Kong high-speed officially opened to traffic operation, this is a high-speed railway with the longest construction time, the most complex engineering type, and the speed reached $350 \mathrm{~km}$ of high-speed railway lines in the world.

On February 6 in 2010, the Zhengzhou-Xi'an high-speed railway was officially opened to traffic. It was the world's first high-speed rail line that can reach the speed of 350 kilometers per hour in a wet loess area.

On December 1 in 2012, Beijing-Harbin high-speed railway was officially opened to traffic. The line was so long as 921 kilometers, which is the first high-speed railway line built in the cold region of the world.

As Hangzhou, Shanghai-Hangzhou-Ningbo and high iron plate camp opened one after another. And the high-speed railway lines operation reached the mileage of 1107 kilometers, the new China's high-speed rail total mileage reached 12,000 kilometers.

In 2014, the new line of railway production in China reached a record high, and the length of railway business exceeded 112,000 kilometers. High-speed railways have more than 16,000 kilometers of business, ranking first place in the world. Among them, the railway construction of the central and western regions reached an upsurge, with the operating mileage reaching 80,000 kilometers, which was accounting for 62.3 percent of the total length of railway business in 
China.

In 2015, in the 13th five-year plan for high-speed railway, China's high-speed railway will reach $30,000 \mathrm{~km}$ by 2020 , and it is expected to cover more than $80 \%$ of the cities in China.

At the end of 2015, China in the medium and long-term railway network planning "in planning" been horizontal "high-speed network basic completed, so far, China's high-speed railway total mileage reached 19,000 kilometers, the world's first place, accounting for over $60 \%$ of the total mileage high-speed railway in the world.

In July 2016, the state revised "the medium and long-term railway network planning" (2016-2030), and it outlined the grand blueprint of the "eight vertical and eight horizontal" high-speed railway network. The term of this plan is 2016-2025, and the long-term outlook is 2030. By 2020, a number of major landmark projects will be completed and put into operation. The railway network will reach 150,000 kilometers, with 30,000 kilometers of high-speed railways covering more than $80 \%$ of the major cities. By 2025 , the railway network will be about 175,000 kilometers, with a high-speed railway of about 38,000 kilometers. By 2030, we will basically realize connectivity within and outside the region, open interregional roads, high-speed railway connectivity in the provincial capital, rapid access to cities and counties, and basic coverage of counties.

\subsection{The Meaning and Advantages of Building a High-Speed Railway}

The construction of high-speed rail can deepen regional openness, which is leading to rapid circulation of resources and frequent intersection will expand the size of the market. It will shorten the time distance and improve accessibility between cities, thus expanding the scope of the radiation of the central city. Therefore, the improvement of traffic conditions will accelerate the economic growth and promote the adjustment and optimization of the spatial pattern of economic activity. The Beijing-shanghai line, the Beijing-Guangzhou line and the southeast coast passenger line have been crowded with cities, and the level of economic development in these areas has increased rapidly. So, does the construction of high-speed railway promote the development of local economy? The answer to this question requires further research and exploration.

Therefore, the purpose of this paper is to study the effect of China's high-speed railway for local economic growth, based on the above analysis. The analysis of the effect of high-speed railway for local industry development, and further explore high-speed impact on development of local economy and industry in different scale cities.

The development of high-speed railway between different areas makes the distance of space and time closer, and it improves the transportation conditions, and it changed the economic geography pattern in our country and changed people's way of daily life, it plays an important role in the economic development of our country. Therefore, the development of high-speed railway is very 
important and meaningful.

Firstly, this paper makes a theoretical discussion and empirical test. New economic geography theory: this theory by centrifugal force and centripetal force to explain how interactions between increasing returns, transportation costs and the factors flow, eventually it will develop completely different economic structure. After the completion of high-speed railway, the transportation cost is reduced and the production factors flow accelerated. The factors of production are further concentrated in a certain area of the city, forming industrial agglomeration and promoting economic development.

Secondly, it provides an empirical basis for the development of the county level high-speed railway stations along the railway line. This paper systematically analyzes the impact on local economic and industrial development when a county built a high-speed railway station. The study of build a county level high-speed railway can provide practical reference value for the city's economic development, regional coordination planning and for the country's economic development to provide policy recommendations.

Advantages: Compared with other transportation ways, high-speed railway has obvious six advantages: the first one is driving speed. The driving speed of high-speed railway is much faster than the highway or ordinary train speed, the speed can reach $250 \mathrm{~km} / \mathrm{h}$ or above. If the distance between two places is within 1000 kilometers, then the high-speed railway has obvious competitive advantage, high-speed rail is often the first choice for people to choose from different ways of traveling. The second advantage is the passenger volume is large. And the annual traffic volume of high-speed railway is much more than that of other transportation modes. Every year, the railway plays an extremely important role in the "Spring Festival travel". High-speed railway is the first choice for the office workers to go home for the Spring Festival because of its fast speed and it will take less time. The third is safe, reliable, and less accidents. Because high-speed railway is automated in a closed environment. The safety guarantee system is perfect, the traffic accidents are rare, and its safety degree is far higher than any other means of transportations. Fourthly, the price is reasonable. Since the birth of high-speed railway, the price of high-speed railway tickets is higher than that of ordinary trains. Because the total amount of resources is certain, scarce resources will be expensive due to scarcity, which is a normal economic phenomenon. High-speed railway ticket is slightly higher price than a normal train tickets, but in the range of acceptable purchase, consumers are willing to pay a certain price to experience the high quality service, so, in the "Spring Festival" and the holidays, people was willing to spend more money in order to save travel time, and had a better holiday experience, high-speed rail ticket is also "one ticket is hard to find"; Fifth advantage is punctuality rate is high. The high-speed railway in the process of running, all equipment adopt the automatic control, so there was less affected by the natural factors, it can be all-weather operate, unless force majeure, such as a sudden earthquake, blizzard, devastating floods and other extreme natural disasters and extreme weather conditions. The high-speed 
railway has one great advantage over the highway, which is that there will be no traffic jam, and in the holiday every year, the expressway is like a large parking lot when the traffic congestion near the toll stations. Compared with the plane, it will not be affected by the weather and delay the departure time. Because of its high punctuality rate, it is not easy to be late, and it will not disrupt the schedule of passengers or delay the working time. Therefore, high-speed railway is becoming the preferred mean of transportation for people. Sixth, energy consumption is relatively low. If the "person/kilometer" unit energy consumption is used as a measure to compare all kinds of transportation means, we can get the minimum is high-speed railway. When the high-speed railway is 1 unit, the plane is 7 units, the car is 5 units, the bus is 2 units. High-speed railway trains are powered by electricity, which can take advantage of various forms of energy resources and do not consume liquid fuels such as oil, and thus do not produce fuel waste gas to pollute the atmosphere [5] [6].

\section{The Economic Effects of High-Speed Rail Construction}

\subsection{The Growth Pole Effect}

The theory of economic growth is a product of great controversy among Western economists about a country's balanced economic growth or unbalanced growth in the late 1940s and 1950s. Economic growth is usually transmitted from one or more "growth centers" to other departments or regions. Therefore, we should choose a specific geographic space as a growth pole to drive economic development. Hornung, Eric (2015) believes that the construction of the railway has contributed to the growth of the urban population on the site, the economic development, and the expansion of the market size [7] [8]. The growth pole effect of building high-speed rail. The various elements flow in the relatively more spacious regional space, making rational allocation, and it will promote the reasonable and long-term development of the urban economy. The construction of new high-speed railway station cities, new jobs will be created with labor demand, which will attract foreign labor force. The new labor will have food, clothing, shelter, line and other basic living conditions of demand, and these requirements will push related industries such as retail services and wholesaling, catering industry, the real estate industry, the development of transportation industry, and will promote the development of these industries continuously produce and development of related industry. The construction of high-speed railway has strong driving effect on regional economic growth. After the successful construction of high-speed railway line, the site cities along the high-speed railway will develop into a new economic growth point in the region, and the growth pole effect is obvious.

\subsection{The Siphon Effects}

Siphon effect, a term used in physics, refers to the one-way flow of water caused by gravitational and potential differences. With the development of economics, 
"siphon effect" didn't also the introduction of economics to explain some economic phenomena, and it endowed with new meaning: refers to a place to attract foreign elements form the poles at the same time, due to other factors too much out of the negative effects of the economic development. With technology development, human capital, capital, information and other elements of the flow, gradient between urban development gap is widening, there have been some factors of production from small and medium-sized cities to the central city of one-way transfer phenomenon, this phenomenon is "siphon effect". The completion of a new high-speed rail line will prompt some companies to try to enter the big cities of high-speed rail. But many cities are ambivalent about building high-speed rail, which is a mixture of "joy and fear". "The former" is looking forward to "taking a piece of the action" with the opportunity to develop high-speed rail. "The latter" is "to make a wedding dress for others", without attracting the self-interested factors, and the advantageous elements of oneself are taken away, "no butterflies, bees are recruited". Big cities and small and medium-sized cities are strong resource competitors. When the big cities are recruiting, it is not clear whether the small and medium-sized cities can see the recruitment of them. High-speed rail site of a city, for its part, at the same time to attract new elements into the local, by other cities attract outflows than inhalation of elements and the elements of "living beyond its means", will appear at this time elements in net outflows, therefore, the city of the possible negative effects of economic growth [9] [10].

\subsection{The Industrial Effect}

The industrial effect of building high-speed rail. The construction of high-speed railway will only bring advantages to the industry which is closely related to its development, but not to all industries. According to the operation experience of high-speed railway at home and abroad, it can be concluded that high-speed railway construction only has strong impetus to some sensitive industries with close relationship with them. Most of these sensitive industries are concentrated in real estate, retail, tourism and other tertiary industries. Transportation is the infrastructure of the national economy, the industrial layout and industrial structure upgrade has had a huge impact, therefore, the success of the high-speed railway construction site will promote the optimization and upgrading of industrial structure of the city. At the same time, due to gather rents, the effects of some of the industry will appear in the process of industrial restructuring agglomeration effect, and there will be a part of the industry diffusion effect, and only be affected by a smaller part of the industry. Therefore, the industrial effect of high-speed railway can be summarized into three types: industrial agglomeration effect, optimization effect of industrial structure and sensitive industrial effect., high-speed rail for cities along the influence of the industry development will increase gradually along with the continuous development of high-speed railway, especially for cities along the railway adjustment upgrade of 
industrial structure will be more obvious. High-speed railway for running speed and reduces the running time, it can shorten the distance of time and space, between the region will strengthen economic ties between area, promoting the mutual flow of each factor, it is proved that the construction of high-speed railway growth pole, driving effects of city's economic development [11] [12].

\subsection{The Same City Effects}

The results of Krugman P (1991) showed that when transport costs are low, there is a strong economies of scale, or there is a higher share of production, a cyclical causal relationship occurs: the more concentrated the manufacturing industry is in a region, the demand share of the region will increase, and this will promote the development of the manufacturing industry, thus driving the arrival of migrants here. The same city effect of building high-speed railway. The same city effect refers to the linkage effect of the city in adjacent areas or more. Along with the continuous improvement of the high-speed railway lines, convenient transportation and relatively shortened the relative distance of space and time, it makes the city a closer link between the city and the city economic boundaries. A city can improve surrounding cities because of its perfect infrastructure and improve service function, the urban material flow between also broke the administrative boundaries between cities, make the material in a wide range of urban agglomeration flow, forming a contact closely, and common development of urban agglomeration economies. This is the new trend of the development of urban modernization and the inevitable outcome of the relationship and cooperation between cities in the development of economic globalization [13] [14].

\subsection{The Urban Structure Effects}

The urban structure effect of building a high-speed railway. The construction of high-speed railway has great influence on the population quantity and urban functional structure of the cities along the route. Due to the role of rent collection, the urban population has moved out and moved in, which in turn leads to the change of urban population size. After the completion of high-speed railway construction, site cities along the route may have new functions due to the change of industrial development. Along the rail line connecting the site in the city, because of the labor force and flow between various factors of production in the city, which makes arriving at the site along the urban population growth can be directly to join the industry development, through the competition and cooperation, to realize the perfect match of labor and industry, forming a new cooperation and division of labor relations. This change has promoted the cities along the high-speed rail line to become new economic growth points, and the radiation will drive the development of surrounding cities. However, because of the "trickle-down effect" and "the polarization effect", the function of some city makes pull effect and continuous development, and then become the center of regional economic growth time, while some cities will appear the negative effects 
of economic development, the original city function has been weakened, the construction of high-speed railway will strengthen the center position in the traffic network in some cities, also will weaken some in interregional contact the disadvantaged secondary node city, this will make the "core" the difference between city and "edge" city become more prominent, the imbalance between them will be increased [15] [16].

\section{Conclusions and Policy Implications}

In the study of economics, experts and scholars often focus on the relationship between transportation infrastructure investment and local economic development. Since the opening of China's first high-speed railway in 2008, China has made remarkable achievements in the development of high-speed railway. Because of this, how to build the high-speed railway will affect the economic and social development of the cities at the county level, which has attracted scholars to try to solve the problem.

On the basis of studying and referring to the existing research results, this paper studies and analyzes the policy influence of high-speed railway on the city of county high-speed railway. Because of the improvement of traffic conditions, the accessibility between different cities will be improved, the transportation costs will be reduced, the links between them will be increased, the transportation capacity will be improved, and the transfer of production factors between regions and cities will be promoted. It optimizes the allocation, increases the utilization factor of production factors, and increases production efficiency. At the same time, it increases investment and the labor demand surges, which increases employment opportunities and changes the pattern of industrial development. The construction of high-speed railways is an important measure to improve the conditions of transportation. The construction of high-speed railways will affect the development of urban industries, and in particular will drive the rapid development of the tertiary industry and change the industrial structure of the city.

As we all know, the development gap between the eastern, central, western, and northeast regions of China is relatively large, and many cities in the western region are still relatively backward and poor. Then, what difference will be made in the economic growth of the county-level units in the eastern, central, western, and northeast regions of the high-speed railway? The economic development of the central and eastern county-level units is well-established, and the transportation resources after improving the traffic conditions are fully utilized. The economic effects brought about by the construction of high-grade railways are obvious, while the economic base in the western regions is relatively weak, and the links between regions are relatively small. There are relatively few opportunities for development.

The following main conclusions are drawn: first, the construction of high-speed rail will have different policy effects on different cities with high-speed railway stations. Second, the construction of high-speed railway can 
promote the significant improvement of fixed asset investment in the cities at the county level, after the construction of high-speed railway. In the end, the construction of high-speed rail will have different effects on "the city of the east county high-speed railway station" and "the city of the high-speed railway station in the central county". High-speed rail lines can promote the development of high-speed rail site at the county level cities in central, and in the eastern county city high-speed rail site has no significant influence.

The evaluation results obtained in this paper have very important policy implications. The results show that the economic development of high-speed rail lines is not a sufficient condition, also will not necessarily promote the rapid development of industries, this site for high-speed rail lines, and high-speed empirical reference of policy implementation and has strong practical significance.

\section{References}

[1] Banerjee. A., Duflo, E. and Qian, N. (2009) On the Railroad: Access to Transportation Infrastructure and Economic Growth in China. http://thred.devecon.org/papers/2012/2012-013_Banerjee_On-the-Road.pdf

[2] Faber, B. (2014) Trade Integration, Market Size, and Industrialization: Evidence from China's National Trunk Highway System. The Review of Economic Studies, 81, 1046-1070. https://doi.org/10.1093/restud/rdu010

[3] Donaldson, D. and Hornbeck, R. (2016) Railroads and American Economic Growth: A "Market Access" Approach. The Quarterly Journal of Economics, 131, 799-858. https://doi.org/10.1093/qje/qjw002

[4] Atack, J., Bateman, F., Haines, M. and Margo, R.A. (2010) Did Railroads Induce or Follow Economic Growth? Urbanization and Population Growth in the American Midwest, 1850-1860. Social Science History, 34, 171-197. https://doi.org/10.1215/01455532-2009-024

[5] Gao, B., et al. (2012) High-Speed Rail and China's 21st Century Strategy. Social Science Literature Publishing House, Beijing.

[6] Krugman, P. (1991) Increasing Returns and Economic Geography. Journal of Political Economy, 99, 483-499. https://doi.org/10.1086/261763

[7] Hornung, E. (2015) Railroads and Growth in Prussia. Journal of the European Economic Association, 13, 699-736. https://doi.org/10.1111/jeea.12123

[8] Duranton, G. and Turner, M.A. (2012) Urban Growth and Transportation. Review of Economic Studies, 79, 1407-1440. https://doi.org/10.1093/restud/rds010

[9] Hu, T.J. and Shen, J.S. (1999) Analysis of the Impact of the Beijing-Shanghai High Speed Railway on Economic Development along the Line. Economic Geography, 19, 101-104.

[10] Song, W.J., Zhu, Q., Zhu, Y.M., Kong, C.C., Shi, Y. and Gu, Y.T. (2015) The Impact of High-Speed Rail on the Development of Cities of Different Sizes. Economic Geography, 35, 57-63.

[11] Xu, C.L. and Yu, Y.L. (2011) Regional Impact and Significance of the Advent of the High-Speed Railway Times. Resources and Environment in the Yangtza Basin, No. 6, 650-654.

[12] Zhang, N.N. and Xu, Y.L. (2005) The Impact of High-Speed Railway on Regional Development along the Line. Areal Research and Development, 24, 32-36.

[13] Sun, T. (2008) The Impact of High-Speed Railway on Urban Development. Modern 
Urban Research, 23, 82-87.

[14] Ping, Y.W. (2001) Significance of Building the Beijing-Shanghai High Speed Railway. China Railway, No. 3, 38-40.

[15] Liu, J.F. and Jiang, X.L. (2012) Countermeasures for the Construction of Modern Logistics System in Hebei Province Based on the Integration of Beijing, Tianjin and Hebei. China Logistics \& Purchasing, No. 11, 56-57.

[16] Wu, Y.S. and Xie, X.L. (1999) A Summary of Foreign High-Speed Railway Development and Socioeconomic Benefits. China Railway, No. 6, 18-23. 